\title{
UK community health visiting: challenges faced during lean implementation
}

\author{
This article was published in the following Dove Press journal: \\ Journal of Healthcare Leadership \\ 27 January 2012 \\ Number of times this article has been viewed
}

\author{
Susan M Carr ${ }^{1,2}$ \\ Pauline Pearson' \\ Lesley Young-Murphy ${ }^{3}$ \\ Barbara Cleghorn ${ }^{4}$ \\ 'Centre for Community Health \& \\ Education Studies Research \& \\ Enterprise, Northumbria University, \\ Newcastle upon Tyne, UK; ${ }^{2}$ School of \\ Health, University of New England, \\ Armidale, New South Wales, Australia; \\ ${ }^{3} \mathrm{NHS}$ North of Tyne, Newcastle upon \\ Tyne, UK, ${ }^{4}$ Newcastle PCT, Newcastle \\ upon Tyne, UK
}

\begin{abstract}
This paper presents an overview of the challenges and potential of lean implementation for the health visiting service in England and examines the rhetoric and the reality of the situation. It is coauthored by academic researchers and senior service providers so as to embrace the multidimensional issues impacting on this subject. If lean thinking is to be implemented in relation to health visiting, it is important to understand how it is likely to be viewed by practitioners and line managers in settings where it is used. In order to contextualize the discussion, an introduction to the roles, systems, and structures of health visiting are provided. The literature on what lean implementation is, what it means, and in particular the application and potential of the approach to primary care and public health services is reviewed. The process and findings from a focus group convened within a large primary care organization in the National Health Service during their lean implementation is reported. The paper concludes that it is important for staff at all levels to see a clear link between strategic aims and objectives and the planning processes operated by providers and commissioners. It appears that the successful introduction of lean thinking should focus more on productive working and thereby reducing waste. This has the potential to refresh workforce models to ensure that health visiting and other practitioners liberate the use of their specialist knowledge and skills. In a context of enhanced partnership working, the stage is then set for providers to add value to the whole system and together improve service user outcomes.
\end{abstract}

Keywords: strategic aims, planning processes, productive working, reducing waste, primary care, service user outcomes

\section{Introduction}

This paper presents an overview of the challenges and potential of lean implementation for the health visiting service in England. It is coauthored by public health nursing academic researchers (SMC, PP), a health visiting locality leader (BC), and a director (LYM) to bring a multidimensional and coordinated approach to the topic. The paper has the following format: an introduction to the roles, systems, and structures of health visiting; a brief review of literature on what lean implementation is and what it means; reporting of focus groups undertaken with health visiting staff in one large primary care organization in the north of England to explore their experience of lean implementation and identify advantages and disadvantages; and finally, a discussion on future directions.

\section{Health visiting: its roles, systems, and structures}

Health visiting in the United Kingdom has its origins in the great public health reforms of the mid-nineteenth century. From an initial focus which was mainly on sanitation,
Correspondence: Professor Susan M Carr Health Improvement Programme, Centre for Community Health \& Education Studies \& Enterprise, Northumbria University, Newcastle upon Tyne, NE7 7XA, UK

Emailsue.carr@unn.ac.uk 
the early health visitors (mainly women) moved to become principally concerned with maternal and child welfare during most of the 20th century. ${ }^{1}$ In the 1970 s, a group of health visitors ${ }^{2}$ developed a set of core principles of health visiting, which have influenced the shape of professional practice ever since. ${ }^{3}$ The principles were to search out health needs, to stimulate awareness of health needs among individuals, families, and communities, to influence policies affecting health and wellbeing, and to facilitate people in engaging with health-enhancing activities. Education and training for the profession were shaped by these, and the role was clearly about the health and wellbeing of whole communities, though maternal and child health remained at the heart of the work.

Whilst the initial structure focused on individual workers, in the late 1980s, with the National Health Service (NHS) restructuring and a policy emphasis on value for money, there were moves to develop skill mix teams in community settings. ${ }^{4}$ Initially the evidence base for this was relatively weak but over the early part of the next decade, questions grew and several studies were undertaken which examined existing patterns of work and different models of development. ${ }^{5-9}$ As the impact of an aging workforce demographic collided with a steep reduction in education commissions, and NHS pressure to reduce budgets, some organizations espoused a corporate caseload model while others developed more systematic roles for support staff, using varying mixes of staff nurses and nursery nurses. ${ }^{10}$

As we have moved into the 21 st century, academic interest has grown in achieving a clearer understanding of the impact of the introduction of differing combinations of staff in a variety of public sector roles. Buchan and Dal Poz, reviewing the evidence about skill mix in the wider healthcare workforce, stated clearly that it was not possible to identify an ideal mix for all health staff and settings. ${ }^{11}$ However, they also said that the evidence they had reviewed indicated that increased use of less qualified staff, though sometimes resulting in greater organizational effectiveness, would not be effective in every situation, and that effectiveness of different skill mixes in healthcare remained underexplored.

Policy documents have made clear that health visitors could make a difference to the health and wellbeing of individuals, families, and communities. ${ }^{12,13}$ Elkan and colleagues reviewed a broad spectrum of existing evidence in relation to the effectiveness of home visiting by health visitors. ${ }^{14}$ They found that home visiting was associated with improvements in parenting skills, enhanced breastfeeding rates, effective behavior change, and a reduction in accidental injury, as well as improvements in cognitive development, and support for parents. McIntosh and Shute explored how the process of health visiting affected parents' perceptions of being supported. ${ }^{15}$ They found that methods of information giving, exploration of decision making, and encouragement of positive parenting affected reported parental confidence and levels of anxiety, increased knowledge, and reduced feelings of isolation. In an environment of financial stringency, an approach which offers to combine organizational improvement with enhanced outcomes for service users is potentially attractive. Lean thinking offers such an approach. ${ }^{16}$

In addition to the economic platform, the health visiting "Call to Action" implementation plan for 2011-2015 provides a real opportunity to consider how lean thinking can make a difference in each one of the three programs of work in order to deliver the vision: (1) growing the workforce, (2) professional mobilization, and (3) aligning the delivery systems. ${ }^{17}$

The operating framework for the NHS 2011/12 states that: "[Primary care trusts should] develop effective health visiting services, with sufficient capacity to deliver the new service model set out in [Health Visitor Implementation Plan] to deliver the Healthy Child Programme, provide greater support to families and develop local community capacity."18

The expansion of the Family Nurse Partnership Program and enhanced partnership working with other local services provide whole system opportunities to ensure that the existing and additional resources add value and make a difference to children, families, and communities.

\section{Literature review}

The literature base on lean thinking and implementation has increased considerably in the past 5 years, with an increasing incidence in healthcare in the United Kingdom. The evidence base however, is still relatively weak, although there is strong indication of potential. Indeed according to Young and McClean, "the question of applicability is still clouded by uncertainty." 19

Lean thinking has a lengthy history, emerging from Toyota car manufacturing as a quality improvement and waste elimination strategy, and has been applied to a range of manufacturing scenarios. ${ }^{20}$

Ward summarizes lean thinking as an opportunity to "redesign services by removing practices or stages in a process that do not add value to the customer." ${ }^{21}$ It is not simply about application of service improvement tools or methods but requires an organizational culture in which 
continuous improvement is supported and can flourish. Appreciating that manufacturing and service delivery comprises multiple systems is core to lean thinking. Focusing on any one system in isolation of others is therefore outwith the lean approach as process problems or difficulties may merely be moved to other systems rather than addressed. This may have unintended consequences for other parts of the system. Lean thinking is based on five principles: value, value stream, flow, pull, and perfection. ${ }^{22}$

1. Value: understanding what customers need and value.

2. Value stream: "those activities that, when done correctly, and in the right order, produce the product or service that the customer values." 22

3. Flow: "work should flow steadily and without interruption from one value adding or supporting activity to the next." 22

4. Pull: in contrast to pushing work "through the system at the convenience of the operators" and reacting to customer demand, in a lean organization work is pulled through the system. ${ }^{22}$

5. Perfection: the above processes should lead to an enhanced understanding of the system, which in turn provides an environment for generation of more improvement ideas and a continuing refinement and perfection process.

Its appeal to healthcare can clearly be seen in the possibility of achieving improved care and reduced cost. It was suggested by de Souza that what makes lean particularly adaptable to a healthcare environment are "staff improvement and the concept of gradual and continuous improvement." 23

Lean thinking or the application of lean principles in healthcare is not a new phenomenon. Virginia Mason Medical Centre (Seattle, WA) introduced a Virginia Mason Production System in 2002 based upon the Toyota Production System. ${ }^{24}$ There are a number of United Kingdom programs that are based upon lean principles in an attempt to make service improvement and reduction of waste mainstream practice. One of the key principles of the Toyota system is respect for its workers and society. Lean when applied within this context is not mean - an important factor that should be at the core of its introduction. ${ }^{25}$ The current global and national economic pressures and the savings that the NHS is required to make to enable reinvestment into frontline care undoubtedly increase the sense of urgency for change. This sense of urgency and creating an environment for people to see and feel the need for change is in line with models of change such as that developed by Kotter. ${ }^{26}$

However, important questions posed in literature to date relate to whether lean thinking can be applied en masse to healthcare or whether there are specific elements particularly applicable to healthcare or indeed across the diversity of healthcare. Radnor and Boaden note that "in general, lean applications have been in nonpatient contact areas which some have argued are more akin to manufacturing processes." 27 Application to healthcare is an issue addressed by Young and McClean who report an analysis of readacross from other sectors. ${ }^{19}$ They suggest that healthcare poses specific challenges, a key one being the presence of multiple value measures. Young and McClean highlight three core issues of evidence, value, and metrics on which healthcare and improvement processes are judged. ${ }^{19}$ These highlight quite fundamental differences and possible barriers, unless consensus is achieved. With respect to evidence they draw attention to key cultural differences of "champion versus researcher, good news versus analysis, trials versus improvement." 19 With respect to value they suggest "a common currency" is required across the clinical, operational, and experiential perspectives. They question the alignment of lean metrics which provide feedback for "coal face" workers of improvements and the conflicting metrics of others in the organization. Radnor and Walley examined the value placed by the public sector on intangible as well as tangible benefits, for example, better understanding of customers or increased staff morale. ${ }^{28}$

Young and McClean suggest that the application of lean methodology in healthcare is complex and fragmented. They state that "uptake is mixed, and practice may be pragmatic rather than pure." 19 Mazzocato et al, reporting the results of a realist review of lean thinking in healthcare, suggest that rather than a holistic approach, there is a dominance of technical applications "with limited organizational reach."29 They go on to suggest that to make real the potential benefits, healthcare organizations need to actively involve senior management, work across functional divides, pursue value creation for patients and other "customers," and nurture a long-term view of continuous improvement. The reality in the United Kingdom, and especially in England, is made even more complex by restructuring of healthcare organizations.

There have been very few reports of the application of lean principles to health visiting. Grove et al did identify opportunities to remove waste from the system in health visiting and suggested that there are considerable opportunities to increase value added activity in health visiting. ${ }^{30}$

\section{Methods}

In order to offer an overview of some of the challenges identified for health visitors and the health visiting service 
within a large primary care organization in NHS during lean implementation, a focus group $(n=7)$ was convened to examine the advantages and disadvantages of such an implementation process. This was an informal element of ongoing service improvement work across the organization. Participants were recruited across geographical localities and from all levels of staff (health visitors, community practice teachers). The staff in the focus group may have been atypical of the wider health visiting workforce; however, a previously identified lack of engagement in lean programs would appear to suggest otherwise. A review of attendance had shown that only one health visitor had attended any specific lean activity, and only just prior to the focus group.

The organization where the focus groups took place had a clear vision and strategic objectives, a staff compact in the form of a staff charter, and a method of service improvement underpinned by a lean philosophy. These are all key areas in the lean sustainability iceberg model. ${ }^{31}$ Strategy alignment, leadership, behavior, and engagement are considered enabling factors. The organization had developed its own conceptual model of organizational development with a central focus on improving the care experience system. The Improving Care Experience System was based upon lean principles and used a stratified approach across the organization. It focused on leadership, culture, clear values, improving the care experience of patients and carers, improving the experience of staff delivering or enabling care, and improving the care experience through partnership working. It was recognized that a whole system approach was required and that the organization was part of the local as well as the health and social care economy. This complemented the regional approach (North East Transformation System) based upon the Virginia Mason Production System approach. Developed in a healthcare organization, the Virginia Mason Production System "requires adopting a paradigm shift from expecting errors and defects, to believing that the perfect patient experience is possible." ${ }^{24}$ It draws on a range of improvement activities.

The organization acknowledged that there needed to be a firm foundation from which to build and used a stratified approach to nurture enquiring minds and creative thinking, encouraging staff to use the four stage cycles (plan the change, do the change, study outcome, act to plan further change or implement) as a framework for service improvement and when sharing outcomes with others. ${ }^{32}$

They had provided open access e-learning training in applied lean methodology and face-to-face training which more than 500 staff successfully completed. A biannual service improvement event provided an opportunity to show case improvements and included a workshop to practice using tools and techniques. All of the work-based learning programs developed in partnership with a local university included service improvement as a core component and encouraged the application of knowledge in practice by completing a service improvement practice project linked to corporate objectives. Staff at all levels across the organization were considered to be at different points in their service improvement and lean journey.

Focus group discussion was recorded on flip charts and on Post-it ${ }^{\circledR}$ Notes (3M, St Paul, MN) for each question. Facilitators wrote up brief notes of the focus group. All flip charts were photographed. Material was collated and thematic analysis was undertaken by all the authors meeting together.

\section{Findings}

If lean thinking is to be implemented in relation to health visiting, it is important to understand how it is likely to be viewed by practitioners and line managers in settings where it is used. Focus group respondents indicated that they understood it as being a process of reducing waste and streamlining to facilitate efficiency, effectiveness, and productivity. Two respondents highlighted improving users' experience as an important dimension.

Respondents' experience of lean to date was varied. Some had read papers, including one about the use of this approach at Toyota. Two had been involved in leadership training. For example, one noted that they had "undertaken Virginia Mason certified leader." There was an awareness of the need to explore and map processes (this was the main tool people were aware of), the need to look at teams and skill mix, and to work with other agencies. Other comments included: "Frustration at evidence of duplication and paperwork" and highlighted perhaps the potential for misuse: "Using staff issues to change and [focus] practice to clinical contacts."

People's concerns about using lean approaches in health visiting were principally about the danger of its use as a cost-cutting exercise rather than focusing on improvement in services. Some respondents felt that there might be reductions in staff numbers. Lack of involvement by service users and by practitioners, and the dangers of losing continuity and face-to-face care were highlighted. One respondent commented that it would need "staff involvement in change [and] authentic leadership." 
Thinking about benefits of lean thinking, respondents in the focus groups focused primarily on the potential for "a service that meets users' needs," with better outcomes for individuals. Others suggested that it would help in developing "systems and processes to support effective working" and a more productive workforce. Increased job satisfaction and enhanced working arrangements were also flagged, with one respondent stressing that she experienced "less frustration at ... admin work duplication." However, only one respondent mentioned that lean could reduce waste of resources. When waste in relation to health visiting was enquired about, repetitive paperwork, patterns of ineffective visiting, and poor use of staff skills were all listed.

Respondents were asked more specifically how lean methods could be used in health visiting. Many of the responses looked at infrastructure, though some addressed workforce design. Several answers focused upon standardizing or supporting administrative functions, or as one person put it: "less paperwork." Other responses suggested that lean methods might bring about "improved information technology provision and training." Integrated documentation and improved access to data on compatible systems were other suggestions. A few responses focused on change or improvement of skill mix and balancing of workload.

Looking at actual experience of using lean methods, there were fewer responses from the group. However, the balance of experience was more towards workforce redesign. Respondents indicated that they had looked at systems and processes within their team and assessed skills within the team, eg, "looking at skills within team for effective use," and that they had explored the use of staff nurses and nursery nurses, as well as secretarial support, within teams. Two respondents indicated that changes had focused on developing clinic provision and enhancing utilization. Outcome measures described by respondents were largely task specific, concerned with utilizing appropriate resources and skills. Respondents felt that resources had been more appropriately targeted, and continuity of care provided to the most vulnerable. Caseloads were felt to have been distributed more equitably. Explicit awareness of techniques employed in lean thinking was limited, but one respondent referred to the use of a "traffic light system."

\section{Discussion}

This paper set out to examine the rhetoric and the reality of the introduction of lean thinking in health visiting. The reason for this focus was that most previous work had looked at hospital-based implementation or addressed specific clinical tasks. Health visiting, focusing on community-based public health work, appeared to present some challenges for a methodology which initially emerged out of manufacturing.

In practice, the nature of the work (promoting health with families and individuals) is not identified as an issue in the implementation of lean thinking. Much more significant appears to be a lack of engagement by staff and an inability for many to make a link between practice and strategic aims and objectives and planning processes. Similarly, at a time when policy has created separation between those who commission and those who provide health services, there appears to be a lack of clarity as to how health visitors might influence commissioning. A key question in this area must be how lean is framed. Is it seen as a tool for financial saving, or a way of addressing service goals more effectively? Some evidence indicated that staff needed to make a link between strategic aims and objectives and the organization's and commissioners' planning processes. There was also indication that lean thinking may be effectively used in combination with other approaches, taking account of the need for effective communication and feedback loops.

An important dimension implicit in focus group material relates to how individuals valued particular groups, including each other. The emphasis placed on lean thinking meeting users' needs and generating better outcomes for individuals suggests that service users are a key stakeholder group, and making a difference for them is a fundamental driver for staff in engaging in lean thinking. Respondents' interest in team processes and workforce redesign perhaps indicates their emerging awareness of the limitations of existing models and the potential of some of their colleagues to contribute to more effective care. It seems that lean thinking can refresh practitioners' thinking in this area. However, whilst work in partnership with other agencies was mentioned, ideas were not developed, suggesting that lean approaches may have less impact in this area.

For health visiting, waste was not a high profile concept amongst practitioners, though of the seven areas identified by Taiichi Ohno ${ }^{33}$ (transportation, inventory, motion, waiting, over processing, overproduction, defect), waste of time/ waiting, in particular, might be familiar. Indeed, when explored, respondents highlighted administrative waste (through duplication and repetition), wasted time in ineffective visiting and, implicitly, some waste of skills within the workforce. However, in the implementation of lean thinking within this organization, the reduction of administrative waste was identified as a high priority. 
Waste through misalignment of delivery and commissioning systems has to inhibit productive working in health visiting and primary healthcare. The implementation of the health visiting delivery plan and the alignment of delivery systems created by the plan promises an environment in which lean thinking can flourish. Implementation should then be able to achieve maximum potential for clients and communities as well as improved health and wellbeing for staff. ${ }^{34}$ Lean methodologies in the multiple, diverse, and disparate delivery contexts met in health visiting potentially provide a creative lens through which to develop and improve practice.

Systems coming into place in health visiting provide a clear framework for the outcomes that the profession needs to achieve. ${ }^{17,18}$ Through professional mobilization to achieve the delivery of the systematized Healthy Child Program and the Family Nurse Partnership program, together with lean thinking, improved outcomes for children, families, and communities can be delivered.

\section{Conclusion}

There are many challenges but also considerable potential value in the introduction of lean thinking into health visiting in the United Kingdom. It is important for staff at all levels to see a clear link between strategic aims and objectives and the planning processes operated by providers and commissioners. It appears that the successful introduction of lean thinking should focus more on productive working and thereby reducing waste as defined by Taiichi Ohno. This has the potential to refresh workforce models to ensure that health visiting and other practitioners liberate the use of their specialist knowledge and skills. In a context of enhanced partnership working, the stage is then set for providers to add value to the whole system and together improve service user outcomes.

\section{Disclosure}

The author reports no conflicts of interest in this work.

\section{References}

1. Billingham K, Morrell J, Billingham C. Reflections on the history of health visiting. Br J Comm Health Nurs. 1996;1(7):386-392.

2. Council for the Education and Training of Health Visitors. An Investigation into the Principles of Health Visiting. London: The Council; 1977.

3. Cowley S, Frost M. The Principles of Health Visiting: Opening the Door to Public Health Practice in the 21st Century. London: Community Practitioners' and Health Visitors' Association; 2006.

4. Kelly TA, O'Leary M. NHS Management Executive Value for Money Unit. The Nursing Skill Mix in the District Nursing Service. London: HMSO. 1992.
5. Lightfoot J. Demonstrating the value of health visiting. Health Visit. 1994;67(1):19-20.

6. Davison N, Pearson P. Sensitivity and care: vital tools for skill-mix review. Nurs Times. 1994;90(43):38-39.

7. Gibbings SM. Dependency, skill mix and grade mix and their effects on health visiting practice. J Clin Nurs. 1995;4(1):43-47.

8. Williams A, Sibbald B. Changing roles and identities in primary health care: exploring a culture of uncertainty. J Adv Nurs. 1999;29(3): 737-745.

9. Richards A, Carley J, Jenkins-Clarke S, Richards DA. Skill mix between nurses and doctors working in primary care-delegation or allocation: a review of the literature. Int J Nurs Stud. 2000;37(3):185-197.

10. Drennan V, Davis K. Trends Over Ten Years in the Primary Care and Community Nurse Workforce in England. London: Faculty of Health and Social Care Sciences, St George's University of London and Kingston University; 2008.

11. Buchan J, Dal Poz MR. Skill mix in the health care workforce: reviewing the evidence. Bull World Health Organ. 2002;80(7):575-580.

12. Department of Health. Making a Difference: Strengthening the Nursing, Midwifery and Health Visiting Contribution to Health and Healthcare. London: Department of Health; 1999.

13. Marmot M. Fair Society, Healthy Lives: A Strategic Review of Health Inequalities in England Post-2010. London: Department of Health; 2010.

14. Elkan R, Kendrick D, Hewitt M, et al. The effectiveness of domiciliary health visiting: a systematic review of international studies and a selective review of the British literature. Health Technol Assess. 2000; 4(13):i-iv, 1-339.

15. McIntosh J, Shute J. The process of health visiting and its contribution to parental support in the Starting Well demonstration project. Health Soc Care Community. 2007;15(1):77-85.

16. Womack JP, Jones DT. Lean Thinking. London: Simon and Schuster; 2003.

17. Department of Health. Health Visitor Implementation Plan 2011-15: A Call to Action. London: Department of Health; 2011.

18. Department of Health. The Operating Framework for the NHS in England 2011/12. London: Department of Health; 2010.

19. Young TP, McClean SI. A critical look at Lean Thinking in health care. Qual Saf Health Care. 2008;17(5):382-386.

20. Womack JP, Jones DT. Lean Thinking: Banish Waste and Create Wealth in Your Corporation. New York: Simon \& Schuster; 1996.

21. Ward S. Thinking lean. Health Serv Rev. 2006;65:12-13.

22. McCarron B. CIPFA Performance Improvement Network. Introduction to "lean thinking." Dec 2006. Available from: http://www.cipfanetworks. net/fileupload/upload/Lean_briefing 1912007311331.pdf. Accessed November 2, 2011.

23. de Souza LB. Trends and approaches in lean health care. Leadersh Health Serv (Bradf Eng). 2009;22(2):121-139.

24. Virginia Mason Medical Center. Virginia Mason Production System. April 6, 2010. Available from: http://www.virginiamason.org/body. cfm?id=5154. Accessed November 2, 2011.

25. Jones D, Mitchell A. NHS Confederation. Lean thinking for the NHS. 2006. Available from:http://www.leanuk.org/downloads/health/ lean_thinking_for_the_nhs_leaflet.pdf. Accessed November 2, 2011.

26. Kotter JP. Leading Change. Boston, MA: Harvard Business School Press; 1996.

27. Radnor Z, Boaden R. Editorial: lean in public services - panacea or paradox? Public Money Manage. 2008;28(1):3-7.

28. Radnor Z, Walley P. Learning to walk before we try to run: adapting lean for the public sector. Public Money Manage. 2008;28(1):13-20.

29. Mazzocato P, Savage C, Brommels M, Aronsson H, Thor J. Lean thinking in healthcare: a realist review of the literature. Qual Saf Health Care. 2010;19(5):376-382.

30. Grove AL, Meredith JO, Macintyre M, Angelis J, Neailey K. Lean implementation in primary care health visiting services in National Health Service UK. Qual Saf Health Care. 2010;19(5):e43.

31. Hines P, Found P, Griffiths G, Harrison R. Staying Lean: Thriving Not Just Surviving. Cardiff: Lean Enterprise Research Center; 2008. 
32. NHS Scotland. Managing clinical effectiveness: Plan, do, study, act (PDSA). 2007. Available from: http://www.clinicalgovernance.scot. nhs.uk/section2/pdsa.asp. Accessed November 2, 2011.

33. The Manufacturing Institute. What is Lean? Introduction to the 7 Wastes. Available from: http://www.manufacturinginstitute.co.uk/ text.asp?pageid=81. Accessed November 18, 2011.
34. West M, Dawson J, Admasachew L, Topakas A. NHS Staff Management and Health Service Quality. Results from the NHS Staff Survey and related data. 2011. Available from: http://www.dh.gov.uk/prod_consum_ dh/groups/dh_digitalassets/documents/digitalasset/dh_129656.pdf. Accessed November 2, 2011.

\section{Publish your work in this journal}

The Journal of Healthcare Leadership is an international, peer-reviewed, open access journal focusing on leadership for the health profession. The journal is committed to the rapid publication of research focusing on but not limited to: Healthcare policy and law; Theoretical and practical aspects healthcare delivery; Interactions between healthcare and society and evidence-based practices;

\section{Dovepress}

Interdisciplinary decision-making; Philosophical and ethical issues; Hazard management; Research and opinion for health leadership; Leadership assessment. The manuscript management system is completely online and includes a very quick and fair peer-review system. Visit http://www.dovepress.com/ testimonials.php to read real quotes from published authors.

Submit your manuscript here: http://www.dovepress.com/journal-of-healthcare-leadership-journal 